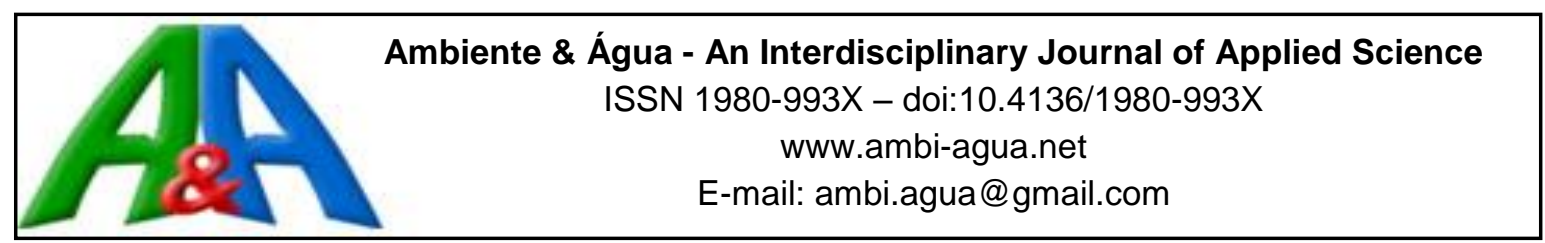

\title{
Fungos isolados da água de consumo de uma comunidade ribeirinha do médio Rio Solimões, Amazonas-Brasil: potencial patogênico
}

\author{
doi:10.4136/ambi-agua.2018
}

Received: 30 Sep. 2016; Accepted: 31 Aug. 2017

\author{
Anni Kelle Serrão de Lima*; Joselita Ribeiro Rodrigues; \\ Ingrid da Silva de Souza; Josy Caldas Rodrigues; Thayana Cruz de Souza; \\ Carolina Rabelo Maia; Ormezinda Celeste Cristo Fernandes
}

\begin{abstract}
Fundação Oswaldo Cruz (FIOCRUZ), Adrianópolis, AM, Brasil
Instituto Leônidas e Maria Deane (ILMD), Laboratório de diversidade microbiana da Amazônia (LDMAIS)

E-mail: anni.kelle@yahoo.com.br, joselitaribeirobr@gmail.com,ingridsouza.bio@gmail.com, josy.silva@fiocruz.br, thayanacruz@gmail.com, carolrmaia@gmail.com,ormezinda.fernandes@fiocruz.br

*Autor correspondente
\end{abstract}

\section{RESUMO}

Os fungos passaram a receber maior atenção como contaminantes de água potável, devido algumas doenças estarem relacionadas a esses microrganismos e ao abastecimento inadequado, principalmente em populações ribeirinhas. Este trabalho verificou a presença de fungos na água de consumo da comunidade ribeirinha, Lago do Limão, Iranduba - AM, e avaliou o perfil de patogenicidade dos fungos isolados. As espécies fúngicas isoladas foram identificadas fenotipicamente e geneticamente. A avaliação dos fungos, quanto ao seu potencial de patogenicidade, incluiu: Crescimento a $37^{\circ} \mathrm{C}$, Produção de Ureases e Proteases. Como resultados, foram isoladas 101 culturas de diferentes gêneros da subdivisão Deuteromycotina. Os gêneros isolados de maior frequência foram Aspergillus spp (41,6\%), Penicillium spp (19,8\%) e Trichoderma spp. (27,7\%). Quanto aos parâmetros de patogenicidade, verificou-se que $95 \%$ das amostras apresentaram positividade quando incubadas a $37^{\circ} \mathrm{C} ; 66,3 \%$ em meio Ágar Christensen e 58,4\% no teste de Proteases. Há escassez de trabalhos que abordam a patogenicidade dos fungos presentes na água, principalmente, em água consumida pelas comunidades ribeirinhas. Espera-se que os resultados deste trabalho possam subsidiar a legislação brasileira estabelecer limites de fungos presentes em água potável.

Palavras-chave: avaliação, patogenicidade, saúde.

\section{A isolated fungi in water consumed by riverside community of the middle Rio Solimões, Amazonas, Brazil: pathogenic potential}

\section{ABSTRACT}

Fungi have received increased attention as drinking water contaminants, because some diseases are related to these microorganisms and inadequate supply, especially in the coastal communities. This study verified the presence of fungi in the water consumed by the riverside community of Lake Lemon, Iranduba, AM and assessed the pathogenicity of isolated fungi. The isolated fungal species were identified phenotypically and genetically. Evaluation of the pathogenic potential of the fungi included: growth at $37^{\circ} \mathrm{C}$, and the production of urease and proteases. As a result, 101 cultures of different genera belonging to the Deuteromycotina 
subdivision were isolated. The most frequently isolated genera were Aspergillus spp (41.6\%), Penicillium (19.8\%) and Trichoderma spp. (27.7\%). The pathogenicity parameters found that $95 \%$ of the samples were positive when incubated at $37^{\circ} \mathrm{C} ; 66.3 \%$ of the fungal isolates were positive in the Agar Christensen media and $58.4 \%$ were positive in the Protease test. There are very few studies that address the pathogenicity of this fungus in Amazon riverine communities. It is hoped that results of this study may support the the passage of Brazilian legislation establishing limits for fungi in drinking water.

Keywords: evaluation, health, pathogenicity.

\section{INTRODUÇÃO}

A água é um recurso insubstituível e indispensável à sobrevivência humana. Nos dias atuais, a distribuição e o abastecimento de água exigem maior atenção, por ser um veículo de transmissão de patógenos, como: bactérias, protozoários, vírus e fungos causadores de inúmeras doenças ao homem (Siqueira, 2010).

De acordo com Nunzio e Yamaguchi (2010), dados revelam que 3,4 milhões de pessoas, principalmente crianças, morrem anualmente por doenças relacionadas à água em todo mundo. Além disso, 2,6 bilhões de pessoas, correspondente a mais de $40 \%$ da população mundial, não utilizam banheiros higiêncios, defecando a céu aberto ou em locais inadequados, o que pode levar a um aumento da incidência de contaminação da água, principalmente em comunidades mais carentes.

O controle e vigilância da qualidade da água para consumo humano é restrito às análises bacteriológicas deixando descoberta as análises micológicas. Os fungos, por serem microrganismos saprófitos, também se mostram presentes nestes sistemas ecológicos, onde o mecanismo de dispersão de propágulos fúngicos ubíquos facilita uma colonização geralmente rápida, modificando sua diversidade morfológica e comportamental refletindo na capacidade de simbiose com outros organismos como plantas e animais em diversos ambientes (Ottoni et al., 2014).

Segundo Restrepo et al. (2001), os fungos apresentam uma capacidade de adaptação em diversos tipos de substratos naturais. Espécies fúngicas, potencialmente patogênicas, alergênicas e toxigênicas, isoladas de água, estão cada vez mais comuns conforme Yamaguchi et al. (2007). Fungos das classes Oomycete e Hyphomycetes são predominantes em águas naturais, a exemplo de Penicillium, Aspergillus e Fusarium que normalmente são encontrados também no solo e no ar. Esses fungos podem apresentar uma capacidade de resistência e desenvolvimento em sistemas de armazenamento e distribuição de água, onde a má qualidade da água de consumo pode ocasionar vários surtos inclusive a morte (Machado, 2010).

$\mathrm{O}$ conhecimento dos fungos presentes na água de consumo possibilita o desenvolvimento de medidas protetoras a modo de evitar as infecções fúngicas ao homem ou qualquer outro tipo de doença que venha a ser acometido por fungos. Desta forma, o presente trabalho teve como objetivo verificar a presença de fungos na água de consumo da comunidade ribeirinha, Lago do Limão, Iranduba - AM e avaliar o perfil de patogenicidade dos fungos isolado.

\section{MATERIAL E MÉTODOS}

\subsection{Coleta e processamento das amostras}

Foram selecionadas 100 casas da Comunidade do Limão, localizada a $30 \mathrm{~km}$ de Manaus no município de Iranduba, Estado do Amazonas. Nelas foram coletadas aproximadamente $1000 \mathrm{~mL}$ de água em sacos estéreis. Ressalta-se que a água coletada era usada para consumo diário e foram transportadas sob refrigeração, para análise laboratorial. Para avaliação 
micológica, as amostras de água foram submetidas ao processo de filtração a vácuo utilizando membrana de $22 \mu \mathrm{m}$. Após esse processo, as membranas utilizadas na filtração foram colocadas em placas de Petri sobre meio Ágar Saboraund (SAB) suplementado com 0,5\% de clorafenicol e incubadas a $28^{\circ} \mathrm{C}$ por sete dias em estufa de crescimento (B.O.D) para avaliação da diversidade fúngica e isolamento das culturas.

\subsection{Isolamento, purificação e identificação fúngica:}

\subsubsection{Identificação clássica}

As culturas isoladas foram repicadas em tubos de ensaios contendo meio $\mathrm{SAB}$, e incubados a $28^{\circ} \mathrm{C}$ por sete dias em estufa de crescimento para purificação. Em seguida, os fragmentos das culturas foram repicados em meio Ágar Extrato de Malte (MEA) para identificação fenotípica (macromorfológica e micromorfológica) em nível de gênero de acordo com a metodologia descrita por (Pitt, 1985; Klich e Pitt, 1988).

\subsubsection{Identificação genética}

Após o isolamento e obtenção de culturas puras foi realizada a extração de DNA total por meio do kit comercial DNeasy Blood \& Tissue Kit (Qiagen), seguindo as recomendações do fabricante. Em seguida, foi realizada a amplificação pela técnica de Reação em Cadeia da Polimerase (PCR), da região correspondente ao espaçador interno transcrito (ITS) ITS1 - 5,8S - ITS2. Para a amplificação da região ITS, foram utilizadas aproximadamente $30 \mathrm{ng}$ de DNA total, ao qual foram adicionados $5 \mu \mathrm{L}$ de Tampão $5 \mathrm{X}$; $0,3 \mu \mathrm{L}$ de GoTaq DNA Polimerase $(5 \mathrm{U} / \mu \mathrm{L})$ (Promega); $0,5 \mu \mathrm{L}$ de dNTP $(10 \mathrm{mM}) ; 0,5 \mu \mathrm{L}$ de cada primer $(10 \mu \mathrm{M})$ e água mili-Q para completar o volume da reação $(25 \mu \mathrm{L})$. Esta mistura de reagentes foi submetida à amplificação com um perfil de temperatura que consistiu em uma etapa de desnaturação inicial a $94^{\circ} \mathrm{C}$ por 5 minutos, seguida de 35 ciclos com desnaturação a $94^{\circ} \mathrm{C}$ por 30 segundos, anelamento a $60^{\circ} \mathrm{C}$ por 1 minuto, e extensão a $72^{\circ} \mathrm{C}$ por 2 minutos. Ao término dos 35 ciclos, foi realizada uma extensão final a $72^{\circ} \mathrm{C}$ por 10 minutos. Os primers utilizados para a amplificação foram ITS1 (5' TCCGTAGGTGAACCTGCGG 3 ') e ITS4 (5' TCCTCCGCTTATTGATATGC 3') (White et al., 1990).

Após purificação, os fragmentos amplificados foram submetidos a reações de sequenciamento, utilizando o kit BigDye Terminator v3.1 Cycle Sequencing Kit (Thermo Fisher Scientific), sendo as sequências nucleotídicas obtidas por eletroforese capilar no sequenciador de DNA ABI 3130xl (Thermo Fisher Scientific) da plataforma de genômica do Instituto Leônidas e Maria Deane (ILMD/FIOCRUZ) ou do Laboratório Temático de Biologia Molecular do Instituto Nacional de Pesquisas da Amazônia (INPA). Após esta etapa, os eletroferogramas foram utilizados para construção de contigs e montagem final de cada sequência, com auxílio de softwares de bioinformática.

\subsection{Parâmetros de patogenicidades}

\subsubsection{Crescimento a $37^{\circ} \mathrm{C}$}

Para o teste de crescimento a $37^{\circ} \mathrm{C}$, as culturas foram transferidas para placas de Petri com meio MEA, e incubadas a $37^{\circ} \mathrm{C}$ por sete dias em estufa de crescimento. As culturas que apresentaram crescimento após o período de incubação foram consideradas como patogênicas (Silva et al., 1999; Neves et al., 2006).

\subsubsection{Ureases}

O teste de urease foi realizado a partir de alíquotas transferidas para tubos de ensaios contendo meio Ágar Christensen e incubadas a temperatura de $28^{\circ} \mathrm{C}$, com observações diárias durante sete dias. Após esse período, um padrão de coloração vermelho - fuccina do meio indicava resultado positivo (Da Silva, 1999; Neves, 2006).

\section{IPABH}




\subsubsection{Proteases}

No teste de protease, as culturas foram repicadas em meio Ágar Protease e incubadas a temperatura de $28^{\circ} \mathrm{C}$ por 48 horas, com observações diárias. Halos translúcidos ao redor da colônia indicavam resultado positivo (Teixeira et al., 2011).

\section{RESULTADOS E DISCUSSÃO}

Das 100 amostras de água selecionadas, obteve-se um total de 322 colônias fúngicas, das quais 101 foram isoladas por apresentarem morfotipos diferentes. Com base nessas características fenotípicas, podemos verificar que dentre as amostras isoladas foram identificados oito gêneros, Aspergillus, Curvularia, Fusarium, Paecilomyces, Penicillium, Rhizopus, Trichoderma e Mucor, pertencentes à subdivisão Deuteromycotina. (Tabela 1). Tendo o gênero Aspergillus, Penicillium e Trichoderma se destacado por apresentar maior abundancia nas amostras em relação aos outros gêneros (Figura 1).

Tabela 1. Ocorrência das espécies de fungos filamentosos isolados da água de consumo da comunidade ribeirinha do Limão-Iranduba/Amazonas.

\begin{tabular}{ccc}
\hline Fungos & $\mathrm{N}^{\circ}$ ocorrência & \% de ocorrência \\
\hline Aspergillus ssp. & 41 & 42 \\
Curvularia ssp. & 1 & 1 \\
Fusarium ssp. & 2 & 2 \\
Mucor ssp. & 1 & 1 \\
Paecilomyces spp. & 2 & 2 \\
Penicillium ssp. & 20 & 20 \\
Rhizopus spp. & 1 & 1 \\
Trichoderma ssp. & 28 & 28 \\
Outros & 5 & 3 \\
\hline Total & 101 & 100 \\
\hline
\end{tabular}

Os fungos da classe Deuteromycota são ubíquos e encontrados onde há matéria orgânica, sendo a maioria saprófitos e, ocasionalmente, patogênicos. Estas espécies são biologicamente mais bem-sucedidas de que todos os fungos e são esperadas em todos os tipos de habitats, incluindo a água. Varo et al. (2007) conseguiram isolar vários fungos filamentosos, dentre os gêneros encontrou-se, Trichoderma, Cladosporium, Aspergillus e Fusarium.

Bandh et al. (2016), ao estudarem a presença de fungos oportunistas nas águas dos lagos em Dal Lake, observaram a abundância de diferentes espécies do gênero Aspergillus, que pode ser atribuída à influência do ambiente, uma vez que é um dos fungos saprófitas do ar, mais comumente encontrados devido à entrada de esgoto provenientes das bacias hidrográficas. No presente trabalho, o gênero de maior ocorrência também foi o Aspergillus spp., seguido do gênero Trichoderma spp.
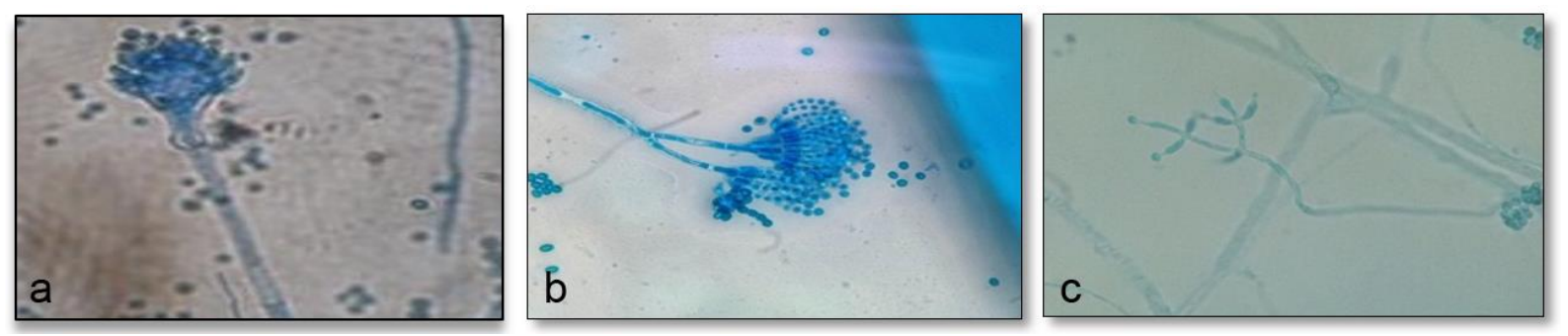

Figura 1. Visualização microscópica dos gêneros Aspergillus (a), Penicillium (b), Trichoderma (c).

Fonte: Autores. 
Quanto à análise genética, foram obtidas sequências nucleotídicas das regiões de interesse (ITS) ITS1 - 5,8S - ITS2, sendo todas essas sequências submetidas à identificação a nível de espécie por meio de comparação com sequências depositadas no banco de dados GenBank, o que possibilitou identificar as seguintes espécies, como Aspergillus aculeatus, Penicillium citrinum, Trichoderma virens, dentre outras (Tabela 2). Mas apesar das regiões sequenciadas serem amplamente utilizadas em diversos estudos para caracterização de espécies fúngicas para alguns gêneros, estas regiões não foram sensíveis o suficiente para a identificação de $60 \%$ das culturas testadas. E por se tratar da diversidade da micobiota amazônica, pode-se estar diante de novas espécies ainda não descritas.

Tabela 2. Espécies identificadas pela taxonomia tradicional e biologia molecular.

\begin{tabular}{ccc}
\hline Taxonomia tradicional & Identificação Blast & Frequência \\
\hline \multirow{2}{*}{ Aspergillus } & Aspergillus aculeatus & 06 \\
Curvularia & Aspergillus giganteus & 03 \\
Fusarium & Curvularia affinis & 01 \\
& Fusarium solani & 01 \\
Penicillium & Penicillium citrinum & 04 \\
& Penicillium rubens & 03 \\
& Penicillium chrysogenum & 01 \\
& Penicillium oxalicum & 02 \\
& Penicillium rolfsii & 01 \\
& Trichoderma virens & 05 \\
Trichoderma & Trichoderma asperellum & 04 \\
& Trichoderma atroviride & 04 \\
& Trichoderma harzianum & 01 \\
& Trichoderma reesei & 02 \\
& Trichoderma appalachiense & 01 \\
& Trichoderma erinaceum & 01 \\
& Trichoderma koningiopsis & 01 \\
\hline
\end{tabular}

\subsection{Análise patogênica das culturas fúngicas:}

Quanto aos resultados dos testes de patogenicidade, observou-se que $96(95 \%)$ das culturas testadas apresentaram positividade quando incubados a $37^{\circ} \mathrm{C}$. O que diferencia do trabalho realizado por Faia (2011), que ao testar 103 fungos isolados de alguns pontos de uma rede de distribuição de água, onde as amostras apresentaram crescimento reduzido ou nulo ao serem submetidas à temperatura a $37^{\circ} \mathrm{C}$.

Das 101 amostras submetidas ao teste de Urease, verificou-se que $67(66,3 \%)$ dos isolados fúngicos apresentaram positividade em meio Ágar Christensen. Esses resultados vêm fortalecendo o trabalho realizado por Souza (2013), em que ele testou 50 isolados de areia de praias que apresentaram uma positividade significativa de $49(98 \%)$ das amostras. A importância da urease na patogenicidade vem estimulando novos estudos pelo fato das ureases se mostrarem facilitadoras de infestação no sistema nervoso central (Feder et al., 2015).

Quanto ao teste de protease, $59(58,4 \%)$ das amostras apresentaram positividade. As proteases possuem um importante papel na degradação de componentes da mucosa como o colágeno e a queratina, assim como de componentes do sistema imunológico (Naves et al., 2013), sendo a produzidas por fungos patogênicos reconhecidas como um importante fator de virulência. Acredita-se que o papel fisiológico das proteases durante a colonização do hospedeiro ocorre pela degradação das barreiras da pele e mucosa, digestão das proteínas para obtenção de nutrientes e ataque dos linfócitos e macrófagos, afetando a defesas imunes (Lima et al., 2012). 
A ocorrência de fungos filamentosos em água de consumo ainda divide opiniões de investigadores, quanto ao fato se a contaminação por fungos tem implicações importantes para a saúde, uma vez que a Portaria n ${ }^{\circ}$ 2.914, do ministério da Saúde de 12 de dezembro de 2011, restringe as análises microbiológicas da água para consumo humano apenas à pesquisa de bactérias Escherichia coli (coliforme), como indicadores de padrão de potabilidade. Porém, a avaliação dos fungos como agentes causadores de processos infecciosos ou micoses é de grande relevância, uma vez que podem apresentar sinais malignos sintomáticos, assintomáticos, graves e de rápida evolução, podendo ainda causar hipersensibilidade imediata ou tardia, promovendo quadros alérgicos ou intoxicações pela eliminação de toxinas ou por ingestão de fungos toxigênicos.

\section{CONCLUSÃO}

As amostras de água da comunidade ribeirinha Lago do Limão, Iranduba - AM apresentaram contaminantes fúngicos. Dentre os oito gêneros encontrados, os gêneros isolados de maior frequência foram Aspergillus spp (41,6\%), Penicillium spp (19,8\%) e Trichoderma spp. (27,7\%). Quanto aos parâmetros de patogenicidade, verificou-se que 95,0\% das amostras apresentaram positividade quando incubados a $37^{\circ} \mathrm{C} ; 66,3 \%$ em meio Ágar Christensen e 58,4\% no teste de Proteases.

Poucos trabalhos que abordam a patogenicidade dos fungos presente na água, principalmente em água de consumo de comunidades ribeirinhas, foram realizados. Entretanto, eles são fundamentais para o conhecimento da população de fungos para elaboração de metodologias mais eficazes para o seu combate. É essencial se conhecer as fontes de infecção, pelo monitoramento constante da qualidade da água de consumo para subsidiar o estabelecimento de limites na legislação brasileira de água potável levando em consideração a patogenicidade dos fungos.

\section{AGRADECIMENTOS}

Ao grupo de pesquisa do Laboratório Diversidade Microbiana da Amazônia com Importância para a Saúde (LDMAIS) e ao Instituto Leônidas e Maria Deane/Fiocruz pelo apoio laboratorial para o desenvolvimento do projeto.

\section{REFERÊNCIAS}

BANDH, S. A.; KAMILI, A. N.; GANAI, B. A.; LONE, B. A. Opportunistic fungi in lake water and fungal infections in associated human population in Dal Lake, Kashmir. Microbiology and Pathology Research Laboratory, v. 93, p.105-110, 2016. http://dx.doi.org/10.1016/j.micpath.2016.01.022

FAIA, A. M. Isolamento e identificação de fungos filamentosos e leveduras em alguns pontos de uma rede de distribuição de água. 2011. Dissertação (Mestrado em biologia Celular e Biotecnologia) - Faculdade de Ciências, Departamento de Biologia Vegetal, Universidade de Lisboa, Lisboa, 2011.

FEDER, V.; KMETZSCH, L.; STAATS, C. C.; FIGUEIREDO, N. V.; BRAUN, R. L.; CARLINI, C. R. et al. Cryptococcus gattii urease as a virulence factor and the relevance of enzymatic activity in cryptococcosis pathogenesis. Centro de Biotecnologia, Universidade Federal do Rio Grande, Porto Alegre. FEBS Journal, v. 282, n. 8, p. 14061418, 2015. http://dx.doi.org/10.1111/febs.13229

KLICH, M. A.; PITT, J. I. A laboratory guide to common Aspergillus species and their teleomorphs. North Ryde: CSIRO, Division of Food Processing, 1988. 116 p. 
LIMA, A. N.; GOMES, B. S.; BRITO, A. L.; OLIVEIRA, R.; MAGALHÃES, O. M. C.; MOTTA, C. M. S. Diagnóstico laboratorial e fatores de patogenicidade de fungo isolado naturalmente de Lhamas (Lama glama - Linnaeus 1758) do parque zoológico de dois irmãos, Recife-PE. Acta Veterinaria Brasilica, v. 6, p. 147-150, 2012. http://dx.doi.org/10.21708/avb.2012.6.2.2326

MACHADO, A. P. S. Uso de técnicas de detecção rápidas de fungos filamentosos na água. 2010. 116f. Dissertação (Mestrado em Tecnologia do Ambiente) - Escola de Engenharia, Universidade do Minho, 2010.

NAVES, P. L. F.; SANTANA, D. P.; RIBEIRO, E. L.; MENEZES, A. C. S. Novas abordagens sobre os fatores de virulência de Candida albicans. Revista de Ciências Médicas e Biológicas, v. 12, n. 2, p. 229-233, 2013. http://dx.doi.org/10.9771/cmbio.v12i2.6953

NEVES, K. C. S.; PORTO, A. L. F.; TEIXEIRA, M. F. S. Seleção de leveduras da Região Amazônica para produção de protease extracelular. Acta Amazonica, v. 36, n. 3, p. 299 306, 2006. http://dx.doi.org/10.1590/S0044-59672006000300002

NUNZIO, B.; YAMAGUCHI, M. U. Prevalência de fungos em água para consumo humano de asilos e creches em Maringá - PR. Centro Universitário de Maringá. Revista em Agronegócios e Meio Ambiente, v. 3, n. 2, p. 113-134, 2010.

OTTONI, L. C. C.; YAMAGUCHI, N. U.; OYAMA, J.; YAMAGUCHI, M. U. Ocorrência de Fungos em água para consumo humano. Enciclopédia Biosfera, Centro Científico Conhecer - Goiânia, v. 10, n. 18; p. 3426, 2014.

PITT, J. I. A laboratory guide to common Penicillium species. Sydney: CSIRO, Division of food processing, 1985.

RESTREPO, A.; MCEWEN, J. G.; CASTANEDA, E. The habitat of Paracoccidioides brasiliensis: how far from solving the riddle? Medical Mycology, v. 39, n. 3, p. 233-41, 2001.

SILVA, E. N. B. da; CAVALCANTI, M. A. Q.; SOUZA-MOTTA, C. M. Pathogenicity characteristics of filamentous fungi strains Isolated from processed oat. Revista de Microbiologia, v. 30, p. 377-380, 1999. http://dx.doi.org/10.1590/S000137141999000400016

SIQUEIRA, L. P.; SHINOHARA, N. K. S.; LIMA, R. M. T.; PAIVA, J. E.; LIMA FILHO, J. L. et al. Avaliação microbiológica da água de consumo empregada em unidades de alimentação. Ciência e saúde coletiva, v. 15, n. 1, p 63-66, 2010.

SOUZA, I. S. Avaliação da patogenicidade de fungos filamentosos isolados da praia da Ponta Negra e praia da Lua na cidade de Manaus/AM. 2013. 27f. Monografia (Licenciatura em Ciências Biológicas) - Centro Universitário do Norte, Manaus, 2013.

TEIXEIRA, M. F. S.; SILVA, T. A.; PALHETA, R. A.; CARNEIRO, A. L. B.; ATAYDE, H. M. (Orgs.). Fungos da Amazônia: uma riqueza inexplorada (aplicações biotecnológicas). Manaus: EDUA, 2011. 255 p.

VARO, S. D.; MARTINS, C. H. G.; CARDOSO, M. J. O.; SARTORI, F. G.; MONTANARI, L. B.; GONÇALVES, R. H. P. Isolamento de fungos filamentosos em água utilizada em uma unidade de hemodiálise. Revista Sociedade Brasileira Medicina Tropical. v. 40, n. 3, p. 326-331, 2007. 
WHITE, T. J.; BRUNS, T.; LEE, S.; TAYLOR, J. Amplification and direct sequencing of fungal ribosomal RNA genes for phylogenetics. In: INNIS, M. A.; GELFAND, D. H.; SNINSKY, J. J.; WHITE, T. J. (eds.). PCR Protocols: a guide to methods and applications. San Diego: Academic, 1990. p. 315-322.

YAMAGUCHI, M. U.; RAMPAZZO, R. C. P.; YAMAGA-OGATTA, S. F.; NAKAMURA, C. V.; UEDA-NAKAMURA, T.; DIAS FILHO, B. P. Yeasts and Filamentous Fungi in Bottled Mineral Water and Tap Water from Municipal Supplies. Brazilian Archives of Biology and Technology, v. 50, n. 1, 2007. http://dx.doi.org/10.1590/S151689132007000100001 